\title{
A Review of Patients Developing Reactions at the East Africa Leprosy Research Centre and Alupe Hospital over 8 Years (1950-1957)*
}

\author{
A. W. MUGENYA \\ Medical Research Officer, \\ East Africa Leprosy Research Centre, Busia, Kenya
}

\begin{abstract}
In this paper is reviewed the incidence of reactions among both in-patients and out-patients at Alupe Hospital and the East Africa Leprosy Research Centre in the period 1950-57. The number of patients who suffer from reactions form only a small percentage of the whole, but the frequency of reactions among those who do get them is high. The complications that follow reactive phases are emphasized, as well as the duration of individual reactions.
\end{abstract}

\section{Introduction}

Leprosy is a chronic disease. However, its usually regular course is sometimes interrupted by bouts of acute exacerbation, which may occur in the lepromatous, tuberculoid and borderline types of the disease. Various explanations have been advanced for these acute exacerbations. Ridley (1969) has suggested that the acute reactions are associated with a bacterial antigen and some alteration in the immunological balance between host and bacillus. Tolentino (1965) thought that these phenomena are due to an allergic reaction to the products of disintegration of the Myco. leprae. Chakravarthy (1966) pointed out that climate may be a factor in the precipitation of reactions. Mitsuda (1954) suggested that the reactions may be due to the toxic products of metabolism of Myco. leprae that enter the bloodstream, while Reiss (1937) was of the opinion that the condition is due to metastatic dissemination of leprosy bacilli. In spite of these diverse suggestions, the exact cause of the reactions remains undetermined.

In practice, these reactions constitute a serious problem for the patient, the leprologist, and the physiotherapist, as has been pointed out by, among others, Furness et al. (1968), Ramu (1967) and Tolentino (1965).

\section{Method}

The present study was therefore undertaken at this Centre to review the clinically diagnosed cases of reaction occurring between 1950 and 1957. The clinical records were used, since most of the patients had been discharged.

Altogether, some 5016 patients were seen during that period; of these, 218 were discharged as not suffering from leprosy. The rest were classified as follows: lepromatous leprosy 1002, tuberculoid 3213, borderline 389, and indeterminate

* Received for publication 24 May, 1972. 
207. Among those 4798 diagnosed as having leprosy, $103(2.35 \%)$ developed reactions subsequently.

\section{Results}

Among those getting reactions, $69(65 \%)$ were males and $36(34 \%)$ were females. Of these, $73(69 \%)$ had lepromatous leprosy, $19(18 \%)$ the tuberculoid type, and $3(12 \%)$ borderline. The youngest patient getting a reaction was 6 years of age, and the oldest 62 years; the mean age was 31 years. In some cases intercurrent infections, social factors, and pregnancy were suspected. In this study only 23 patients $(22 \%)$ had some problem associated with their reactions; these factors are detailed in Table 1 .

TABLE 1

factors that led to some of the reactions

\begin{tabular}{lc}
\hline & \\
\hline Pharyngitis & 1 \\
Laryngitis & 1 \\
Hepatitis & 1 \\
Tonsillitis & 1 \\
Chronic osteomyelitis & 1 \\
Pneumonia & 1 \\
Cellulitis & 1 \\
Dysentery & 2 \\
Mumps & 2 \\
Pregnancy & 3 \\
Smallpox vaccination & 2 \\
Emotional problems & 2 \\
Streptomycin injection & 1 \\
& 19 \\
\hline
\end{tabular}

Some of the patients experienced several distinct reactions. Job and Macaden (1963) reported that reaction frequently recurs. Furness et al. (1968) observed up to 20 reactions in some of their 6 patients with lepromatous leprosy.

Table 2 shows the number of distinct reactions per patient correlated with the type of leprosy.

TABLE 2

Number of distinct reactions per individual patient correlated with type of leprosy

\begin{tabular}{crrr}
\hline 9 & 2 & & \\
8 & 2 & & \\
7 & 2 & & \\
6 & 3 & & \\
5 & 7 & & 3 \\
4 & 10 & 3 & 5 \\
3 & 9 & 16 & 5 \\
2 & 9 & 19 & 13 \\
1 & 29 & 73 & \\
Total & & 19 & \\
\hline
\end{tabular}


Table 2 indicates that reactions are most frequent in patien ts with lepromatous leprosy. In some cases the reactions persisted for long periods.

TABLE 3

Showing complications following reactive phases of leprosy. For eye, foot and hand grading, reference should be made to the W.H.O. Bulletin 1968

\begin{tabular}{lccc}
\hline \multicolumn{1}{c}{ Lesion } & \multicolumn{3}{c}{ Classification of leprosy } \\
& Lepromatous & Tuberculoid & Borderline \\
\hline Iritis & $8(1)$ & 1 & \\
Blindness & 1 & 1 & 2 \\
Foot, grade II & $16(4)$ & 4 & \\
Foot, grade III & 10 & 3 & \\
Pyrexia & 4 & 3 & \\
Hand, grade II & 1 & 3 & \\
Hand, grade III & 1 & & \\
Dacryocystitis & 2 & & \\
Leprous myositis & 6 & & \\
Gynaecomastia & 8 & & \\
Arthritis of various joints & 2 & & \\
Orchitis & 6 & & \\
Pyomyositis & 1 & & \\
Lymphadenitis & 1 & & \\
Uveitis & 7 & & \\
Scleritis & 2 & & \\
Neuritis & & & \\
Periostitis & & & \\
\hline
\end{tabular}

Brackets indicate unilateral lesions.

Reactions are commonly the prelude to complications of various kinds, such as acute oedema of the hands, feet, and face (Gurkhale and Kurkure, 1958), orchitis in lepromatous and borderline leprosy (Job, 1963; Tilak, 1968) and deformities (Furness et al., 1968).

In this study, complications as shown in Table 3, have been noted as following reactive phases of leprosy.

Patients with lepromatous leprosy tend to have a greater number of complications following leprosy reactions, and in those with tuberculoid leprosy the deformities are more severe following reactive episodes.

\section{References}

Chakravarthy, A. K. (1966). Climate and reactions in leprosy. Leprosy in India 38.

Furness, M. A., Karat, A. B. A. and Karat, S. (1968). Deformity in the reactive phases of leprosy. Lepr. Rev. 39, 135.

Gurkhale, B. D. and Kurkure, N. B. (1958). Phenol red excretion test of kidney function in leprosy patients. Indo. J. Med. Sci. 12, 331.

Job, C. K. and Macaden, V. P. (1963). Leprous orchitis in reactional borderline cases. Int. J. Lepr. 31, 273.

Mitsuda, K. (1954). On the aetiology of ENL and metabolism of leprosy bacilli. (Abst) Int. J. Lepr. 22, 356.

Ramu, G. (1967). Treatment of lepra reactions. Leprosy in India 39, 2.

Reiss, F. (1937). Erythema nodosum leprosum. Int. J. Lepr. 5, 427.

Ridley, D. S. (1969). Reactions in leprosy. Lepr. Rev. 40, 77.

Tilak, C. T. (1968). Acute epididymo-orchitis in lepromatous leprosy. Lepr. Rev., 39, 31.

Tolentino, J. G. (1965). Course of erythema nodosum leprosum. Leprosy in India 37, 233. 